\title{
General practitioners in partnership with management: an organisational model for debate
}

\author{
N Starey, N Bosanquet, J Griffiths
}

\begin{abstract}
The role of general practitioners is changing and expanding. Doctors have more control over the treatment received by their patients but remain largely unaccountable to the public and management. This article proposes an organisational model for integrating primary and secondary care which retains the advantages of fundholding while giving management control over overall strategy. It proposes that general practitioners control funds for all primary and secondary care. Secondary care will be contracted through a joint team of managers and an elected general practice executive committee. A new health care purchasing authority will contract for primary services with individual practices or primary care provider units. General practitioners will have local contracts reflecting their desire to provide an expanded range of services and the needs of the community.
\end{abstract}

Can general practitioners exchange the illusion of clinical freedom for the reality of effective power? The introduction of the internal market into the NHS has implications for the roles of and relationships between doctors and managers. General practitioners have gained influence over the care their patients receive through the fundholding scheme and through their influence on health authority purchasers. These and other factors (box) are changing the role of general practitioners and an opportunity exists to expand the function of primary care. If general practitioners are to be effective in this expanded role an organisational framework is needed to integrate primary care into the wider health service.

Integrating primary care into the contracting framework of the health service will have advantages for patients, doctors, and managers but general practitioners could see it as a threat to independence rather than an end to isolation. A partnership needs to be established between doctors and management with both controlling resources so that they are interdependent.

Burnham Surgery,

Burnham on Crouch, Essex CM0 8SJ

N Starey, general practitioner fundholder

University of London N Bosanquet, professor of health policy

Oxfordshire Family Health Services Authority, Oxford J Griffiths, general manager

Correspondence to: Dr Starey. fore ho effective managerial in relationship concerned with regulation rather than a partnership devoted to improving patient care. The national contract also makes it difficult to tackle variation in the quality of primary care so that

\section{Factors affecting general practitioners' role \\ External forces: \\ - Devolution of care \\ - Consumerism \\ Internal pressures: \\ - Professional accountability \\ - Vocational training \\ - 1990 contract \\ - Community car \\ - Fundholding \\ - Medical audit \\ - General management \\ - Role uncertainty}

populations with the greatest need too often receive the worst quality care.'

Overall the present arrangements are messy and are causing tension, fragmentation, and confusion between general practitioners' roles in purchasing and provision. Management's need for accountability is not satisfied and doctors are uncertain about the balance between their clinical and managerial roles.

The relationship between general practitioners and district health authorities needs to be explicitly recognised as one of mutual dependence rather than competition. Goodwill can permit effective cooperation for purchasing of secondary care but goodwill is ephemeral when difficult decisions have to be made.

\section{Accountability}

General practitioners are accountable to their patients, their peers, and family health services authorities for performance against their contract. The expanding role of general practitioners, ${ }^{2}$ along with the 1990 contract, the establishment of family health services authorities, and the introduction of medical audit have increased accountability, but general practitioners have been demotivated by the imposition of a contract that increased their administrative burden without clear evidence of clinical benefit. ${ }^{3}$

Nevertheless, society will no longer accept that a self governing profession can be unaccountable for its exercise of power and its use of resources. Increased accountability is being demanded of all public services. Self regulation through medical audit, postgraduate education, and possibly professional reaccreditation are only a partial answer because they give no input to consumer or management.

Cooperation between general practitioners and district health authorities requires mutual accountability. The authority should be accountable to general practitioners for its purchasing performance and general practitioners should be accountable for the purchasing plans they advocate. ${ }^{4}$ Neither the authority nor general practitioners can be efficient purchasers in isolation-they need each other's skills and experience. 


\section{Fundholding only a partial solution}

Early experience with the fundholding scheme has shown that general practitioners can be effective purchasers of care. Their success has resulted from:

- Redefining and reinforcing their relationship with consultants

- Finding spare provider capacity and moving appropriate volumes of work to those areas

- Combining direct knowledge of the needs of patients and of the capabilities of providers

- Using negotiating skills, developed in the consulting room, to make providers address quality issues which general practitioners have previously been unable to influence.

Any new model must preserve these very real advantages. None the less continued expansion of fundholding will lead to excessive management costs, difficulties of coordination in contracting between growing numbers of purchasers, and lack of effectiveness. The quality of primary care teams varies greatly and the success in motivated practices who have opted for fundholding cannot be extrapolated too far. Similarly, general practitioners are unlikely to have the management resources to contract for the full range of services required by a local population. ${ }^{5}$ Expansion of fundholding would not allow for representation of other professional and lay groups in the purchasing process, and would be difficult for family health services authorities to monitor and manage. In short universal fundholding would give too much power to general practitioners and deny effective management of the health service.

\section{A new partnership}

We propose a model for organisation of health services that defines a different relationship between general practitioners and NHS management (figure). The model is an extension of those discussed by Foster. ${ }^{6}$ The principles behind the model are firstly, that management's objective is to commission or provide effective, efficient services to meet the needs of the community it serves within finite resources. Secondly, management does not have all the knowledge required to determine how to meet its objective. Thirdly, management should be accountable to the population and to central government for its perform-

Model for purchasing partnership

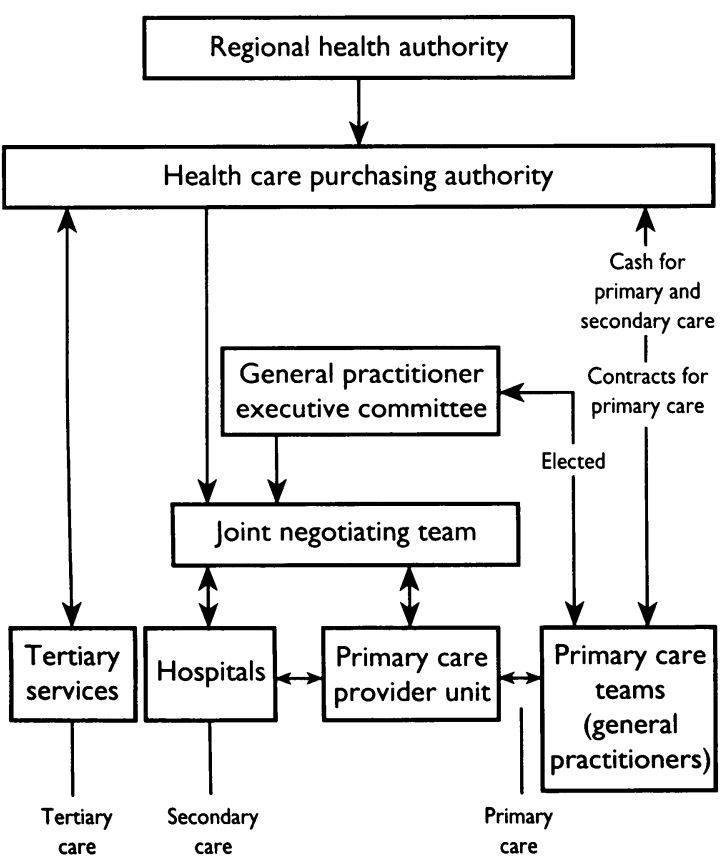

ance. Fourthly, general practitioners are the most logical agent of the patients' demands. Fifthly, general practitioners should be accountable to both patients and management for the process and outcome of the care they provide. Sixthly, general practitioners need to keep their independent contractor status to maintain the trust between doctor and patient, and, finally, family doctors must accept a reconciliation between their long term relationship with the individual patient and the needs of the wider community.

The model requires a new integrated health care purchasing authority with integrated budgets, separation of purchasing and provision in primary care, local contracting with general practice, establishment of a general practice executive committee, and purchasing of secondary care by a joint team representing general practitioners and management, each controlling resources.

\section{How the model will work}

Funds will flow through primary care to secondary care. General practices will control funds for all health care except tertiary care and contingencies and will contract for secondary care services through a partnership between management and the general practice executive committee. The budgets for primary and secondary care will need to be integrated to permit appropriate transfer of resources.

This change would open up a new potential for managers and doctors to invest in shared programmes. Such integration is even more important when money is limited. It seems likely that in the next few years funding will be increased minimally and competition will also grow. Shifting funds to primary care under the existing system will create some new opportunities, but only if general practitioners succeed in relating to a new managed system. Our model will also allow practices to contract for new services to meet local needs. $^{7}$

\section{GENERAL PRACTICE EXECUTIVE COMMITTEE}

This elected committee will have some similarities to the local medical committee and could evolve from it. A committee of 10-12 doctors, each representing a constituency of 20-30000, should be sufficient to service the committee's obligations. It would need management resources, and some members would have to reduce their commitment to general medical services. As with fundholding the committees' responsibilities would include collection and analysis of information, assessment of needs, service specification, negotiation and monitoring of contracts, all of which would be carried out in partnership with the purchasing authority. Central funding of the committee will release resources currently dedicated to managing fundholding. ${ }^{8}$

\section{HEALTH CARE PURCHASING AUTHORITY}

The authority, formed by merging the commissioning functions of the family health services authority and the district health authority, will contract with primary care for defined services-general medical, community nursing, chiropody, family planning, etc. The authority will assess the community's health needs and reflect national and regional priorities.

The authority will be able to direct resources to meet its own priorities for service development. Control of prescribing budgets will be important for effective operation of our model. The authority, in agreement with individual practices, will be able to transfer resources from and to prescribing. This ability is a major incentive within fundholding.

Primary care contracts will be monitored by the purchasing authority and could include medical audit 
and reaccreditation in the future. ${ }^{9}$ The authority will need to involve local consultants and general practitioners from outside the district in audit and reaccreditation.

\section{PRIMARY CARE PROVIDER UNIT}

This unit or trust will be formed from the provider arms of the current community unit and family health services authority. The unit will contract for community services with the purchasing authority or general practice executive committee team or with individual practices or the private sector. Some competition for the provision of primary care and community services will therefore be introduced.

\section{PRIMARY HEALTH CARE TEAMS}

General practitioners and primary health care teams will negotiate a contract with the purchaser and provide services under the contract. Not all practices will want to contract for an expanded range of services and local circumstances will also affect contracting decisions. The purchaser may contract with the primary care provider unit instead of primary care teams. Primary care teams will manage their own budget for staff, prescribing, general medical services, etc, and be accountable to the purchaser for their performance.

The model envisages that a regional management tier will have an important role in strategy development, monitoring, and accountability. ${ }^{10}$

\section{Consequences of the model}

The model will give general practitioners the enhanced influence, powers, and responsibilities of fundholders without the administrative burden. They will have a flexible local contract focusing on the needs of their patients. Doctors elected to the general practice executive committee will have additional purchasing responsibilities.

Flexible contracting will increase accountability to management and make management sensitive to the needs of patients. Integration of primary and secondary care is central to an internal market driven by primary care and should encourage a needs led rather than a service dominated approach.

Under our model contracting may cause difficulties with dispensing, deputising, partnership agreements, profitability, and investment in premises. Arbitration will be needed to prevent exploitation by the purchasing authority. The national contract has had many successes and there is a danger these could be threatened by fragmentation.

The model requires that general practitioners and managers develop new skills particularly in contracting. The evidence that contracting is an efficient mechanism in the NHS is still limited. General practitioners will be concerned that purchasing pressures will disturb the doctor-patient relationship, and doctors' perception of their role as the patient's friend and ally.

\section{Conclusions}

Our model is one possible means of enhancing the benefits of the NHS reforms while minimising some of the problems of fragmentation. The model gives a clear role to general practitioners, reduces their administrative burden, and will stimulate the development of primary care services. A strong contracting framework will be coordinated right across the NHS, balancing the increased responsibilities and power of general practitioners and their accountability for the outcome of the care they provide.

1 Tudor Hart J. The inverse care law. Lancet 1971;i:405-12

2 Department of Health. Caring for people. London: HMSO, 1989. (Cmnd 849.) O'Dowd TC, Wilson AD. The future of general practice: set menus and clinical freedom. BMf 1991;303:450-2.

Taylor D. Developing primary care: opportunities for the 1990s. London: King's Fund Institute, 1991.

5 Glennerster H, Matsagnis M, Owen P. A foothold for fundholding. London: King's Fund Institute, 1992

6 Foster A. FHSAs: today's and tomorrow's priorities. London: Department of Health, NHSME, 1991.

7 Bosanquet N. The future of general practice: family doctors and payment systems: the local option. $B M$ I $^{1991 ; 303: 233-4 .}$

8 Roland $M$. The future of general practice: fundholding and cash limits in primary care: blight or blessing. $B M \mathcal{F}$ 1991;303:171-2.

9 Irvine D. Managing for quality in general practice. London: King's Fund Institute, 1990.

10 North East Thames Regional Health Authority. Primary health care in the 90s-a strategic statement. London: North East Thames Regional Health Authority, 1991

(Accepted 1 December 1992)

\title{
The Future of FHSAs
}

\section{FHSAs and prescribing}

\author{
Rhona Panton
}

This is the fifth and final article in a series of articles on the future of family health services authorities

Department of Pharmacy Policy and Practice, Keele University,

Keele ST5 5BG

Rhona Panton, head of

department

Series editor:

Dr Andrew Harris

BMF 1993;306:310-4
Prescribing by general practitioners cost the NHS $£ 2 \cdot 3$ billion in 1991 - the biggest single cost after staffingand the drug bill is now rising at $11 \%$ a year. Family health services authorities and their professional advisers are charged with the challenging task of "improving the quality and cost effectiveness of prescribing," but any consideration of prescribing costs requires an understanding of how they are affected by factors outside the family health services authority's control. ${ }^{\prime}$ These include price regulation by the government; differential pricing between hospitals and the community; the use of generic and branded products; and the prescription charge, which conceals from the general public the true cost of medicines.

\section{Containing costs}

In most developed countries the pharmaceutical industry is an important part of the economy and its products contribute directly to health gain. Governments, which are purchasers, are faced with the dilemma of safeguarding the benefits while containing the price of drugs. The ability to develop new drugs is now greater than most countries' ability to pay for them without rationing or screening systems-for example, France controls individual prices and Germany has initiated a reference system which pays a basic price for all drugs in the same category. ${ }^{2}$ In Great Britain the government's control system is the prescription pricing regulation scheme, a voluntary agreement between the industry and the government that agrees profitability on NHS business. A measure of the scheme's effectiveness is that the United Kingdom has the fifth highest drug prices in Europe (about where we should expect to be). ${ }^{3}$ The industry recognises the pressures to contain costs and knows that it must concentrate on developing clearly better products, work towards European standardisation of prices, and 